tracts, and an increase of $0.17 \mathrm{~km}[0.10,0.23]$ in urban tracts.

Conclusions Disparities in proximity to stroke care were worse in non-urban areas than in urban areas. Non-urban census tracts with greater representation of elderly, American Indian, or uninsured persons, or low median income, were substantially more distant from certified stroke care. Quantifying disparities in proximity to timely stroke care can inform ongoing efforts for infrastructure improvements that reduce inequalities in access to care.

Disclosures C. Yu: None. T. Blaine: None. P. Panagos: None. A. Kansagra: None.

\section{P-039 FLOW DIVERTERS FOR TREATMENT OF ICA LOOP DISSECTIONS OR ICA DISSECTIONS WITH ASSOCIATED PSEUDOANEURYSM}

'J Singh*, ${ }^{1} \mathrm{~A}$ Kuhn, ${ }^{2} \mathrm{~K}$ de Macedo Rodrigues, ${ }^{1} \mathrm{~F}$ Massari, ${ }^{1} \mathrm{M}$ Gounis, ${ }^{1} \mathrm{~A}$ Puri. ${ }^{1}$ Division of Neurointerventional Radiology, Dept of Radiology, New England Center for Stroke Research, University of Massachusetts Medical Center, Worcester, MA; ${ }^{2}$ Greensboro Radiology, Greensboro, NC

\subsection{6/neurintsurg-2021-SNIS.75}

Purpose Cervical internal carotid artery (ICA) loop dissections or dissections with associated pseudoaneurysm can pose a treatment challenge. Flow diverters are able to reconstruct vessel loops, treat the injured vessel and exclude an associated pseudoaneurysm from the parent artery.

Material and Methods We retrospectively reviewed our prospectively maintained Neuro IR database and identified all patients with ICA dissections primarily treated with flow diverters between July 2017 and September 2020. Patient demographics, procedural data, imaging follow up results and clinical outcome information was also collected.

Results A total of 11 patients were identified (9 males) with a mean age of 59.2 years (range 43 - 85 years). The patients had 7 ICA loop dissections with associated pseudoaneurysm in 2 cases, 3 focal ICA dissections with associated pseudoaneurysm and one long segment ICA dissection with associated pseudoaneurysm. Six lesions were treated with the Surpass Streamline flow diverter and 5 with the Pipeline Embolization device. A single flow diverter was placed in 4 cases, two flow diverters were placed in 1 case, combination of flow diverters and (carotid) stents were placed in the remaining cases and are listed in table 1. Two patients were lost to follow up and another 2 have not reached their follow-up time point yet. Two patients died, one as a result from his stroke burden with which he initially presented and one patient due to a large intraparenchymal hematoma in the setting of dual antiplatelet therapy. Three to 6-month angiogram follow up is available in 4 patients which showed near complete pseudoaneurysm occlusion in 2 cases and complete occlusion in the other 2 cases (figure 1); all cases

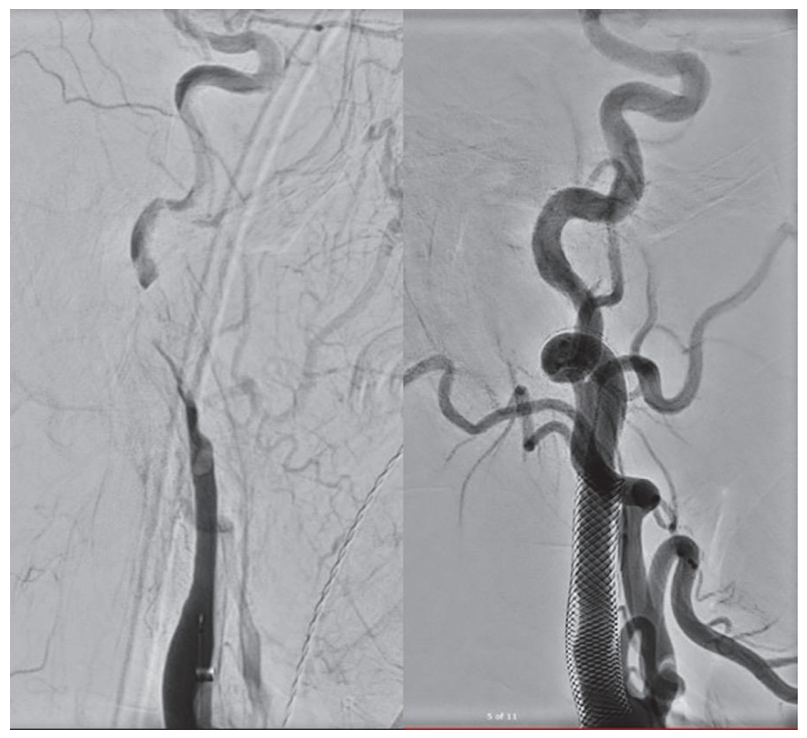

Abstract P-039 Figure 1

\begin{tabular}{|c|c|c|c|c|c|c|c|c|}
\hline Patient & Laterality & Presentation & Dissection & FD and Size(s) & Stent(s) & Follow up time & Follow up result & $\begin{array}{l}\text { Last known } \\
\text { mRS }\end{array}$ \\
\hline 1 & Right & Stroke & Loop dissection & Surpass $5 \times 40,5 \times 30$ & Wallstent $8 \times 36$ & Lost to follow up & - & 2 \\
\hline 2 & Left & Stroke & Loop dissection & Surpass $5 \times 40$ & Wallstent $8 \times 36$ & - & - & 6 \\
\hline 3 & Right & Stroke & Loop dissection & Surpass $5 \times 40,5 \times 40$ & Wallstent $8 \times 36$ & Not reached & - & 0 \\
\hline 4 & Left & Stroke & Loop dissection & Surpass $5 \times 50,5 \times 40$ & - & Lost to follow up & & 0 \\
\hline 5 & Left & Stroke & $\begin{array}{l}\text { Loop dissection with } \\
\text { pseudoaneurysm }\end{array}$ & Surpass $4 \times 50$ & - & Not reached & & 2 \\
\hline 6 & Left & Stroke & $\begin{array}{l}\text { Focal dissection with } \\
\text { pseudoaneurysm }\end{array}$ & Surpass $5 \times 30$ & - & 6 months & $\begin{array}{l}\text { No residual, patent } \\
\text { device }\end{array}$ & 3 \\
\hline 7 & Right & Stroke & $\begin{array}{l}\text { Focal dissection with } \\
\text { pseudoaneurysm }\end{array}$ & Pipeline $4.75 \times 25$ & - & - & - & 6 \\
\hline 8 & Right & Neck pain & $\begin{array}{l}\text { Focal dissection with } \\
\text { pseudoaneurysm }\end{array}$ & $\begin{array}{l}\text { Pipeline } 5 \times 16,4.75 \times 18, \\
4.75 \times 18,4.75 \times 16\end{array}$ & Acculink $6 \times 20$ & 6 months & $\begin{array}{l}\text { Near complete, patent } \\
\text { devices }\end{array}$ & 0 \\
\hline 9 & Right & Headache & $\begin{array}{l}\text { Long segment dissection with } \\
\text { pseudoaneurysm }\end{array}$ & Pipeline $5 \times 35,5 \times 33$ & Precise $5 \times 20$ & $\begin{array}{l}6 \text { months and } 20 \\
\text { months }\end{array}$ & $\begin{array}{l}\text { Complete occlusion, } \\
\text { patent devices }\end{array}$ & 0 \\
\hline 10 & Right & Stroke & Loop dissection & Pipeline $4 \times 25$ & $\begin{array}{l}\text { Neuroform EZ } \\
\text { Enterprise }\end{array}$ & 3 months & $\begin{array}{l}\text { Near complete, patent } \\
\text { devices }\end{array}$ & 0 \\
\hline 11 & Left & Stroke & $\begin{array}{l}\text { Loop dissection with } \\
\text { pseudoaneurysm }\end{array}$ & Pipeline $5 \times 35$ & - & 12 months & $\begin{array}{l}\text { Complete occlusion, } \\
\text { patent devices }\end{array}$ & 3 \\
\hline
\end{tabular}


showed patent flow diverter(s) with or without stent(s). One patient had a 1 year follow up only which showed complete occlusion of the pseudoaneurysm with a patent flow diverter. No significant in-device stenosis was identified in any followup case.

Conclusion Use of flow diverters, in some cases in conjunction with (carotid) stents, is an effective treatment option for cervical carotid artery dissections, especially loop dissections with or without associated pseudo aneurysms.

Disclosures J. Singh: None. A. Kuhn: None. K. de Macedo Rodrigues: None. F. Massari: None. M. Gounis: 1; C; National Institutes of Health (NIH), the United States - Israel Binational Science Foundation, Anaconda, ApicBio, Axovant, Cerenovus, Cook Medical, Gentuity, Imperative Care, InNeuroCo, Magneto, Mic. 2; C; Cerenovus, Imperative Care, phenox, Medtronic Neurovascular, Route 92 Medical, Stryker Neurovascular. 4; C; Imperative Care, InNeuroCo and Neurogami. A. Puri: 1; C; NIH, Cerenovus, Stryker Neurovascular and Medtronic. 2; C; Stryker, Cerenovus, Medtronic, Microvention, QApel, Perfuze Medical, Arsenal Medical, Merit Medical. 4; C; InNeuroCo Inc, Galaxy therapeutics, Agile Medical, Perfuze medical and NTI.

\section{P-040 MAJOR COMPLICATIONS OF DURAL VENOUS SINUS STENTING FOR IDIOPATHIC INTRACRANIAL HYPERTENSION: CASE SERIES AND MANAGEMENT CONSIDERATIONS}

${ }^{1} \mathrm{R}$ Townsend*, ${ }^{2} \mathrm{~A}$ Jost, ${ }^{3} \mathrm{M}$ Amans, ${ }^{4} \mathrm{~F}$ Hui, ${ }^{5} \mathrm{M}$ Bender, ${ }^{6} \mathrm{~S}$ Satti, ${ }^{7} \mathrm{R}$ Maurer, ${ }^{8} \mathrm{~K}$ Liu, ${ }^{9} \mathrm{~W}$ Brinjikji, ${ }^{1} \mathrm{~K}$ Fargen. ${ }^{1}$ Neurosurgery, Wake Forest, Winston salem, NC; ${ }^{2}$ Wake Forest, Winston salem, NC; ${ }^{3}$ Neurosurgery, University of California-San Francisco, San Francisco, CA; ${ }^{4}$ Neurosurgery, Johns Hopkins Hospital, Baltimore, MD; ${ }^{5}$ University of Rochester Medical Center, Rochester, NY; ${ }^{6}$ Christiana Care Health System, Newark, DE; ${ }^{7}$ Penn State Health, Hershey, PA; ${ }^{8}$ University of Southern California, Los Angeles, CA; ${ }^{9}$ Mayo Clinic, Rochester, MN

\subsection{6/neurintsurg-2021-SNIS.76}

Introduction Venous sinus stenting (VSS) is a safe, effective, and increasingly popular treatment option for selected patients with idiopathic intracranial hypertension (IIH). Serious complications associated with VSS are rarely reported.

Methods Serious complications after VSS were identified retrospectively from multicenter databases. The cases are presented and management strategies are discussed.

Cases Six major acute and chronic complications after VSS were selected from a total of 811 VSS procedures and 1466 venograms for IIH. These included an acute subdural hematoma from venous extravasation, cases of both intraprocedural and delayed stent thrombosis, an ultimately fatal cerebellar hemorrhage resulting in acute obstructive hydrocephalus, venous microcatheter perforation during venography and manometry, and a patient who developed SAH and SDH after cerebellar cortical vein perforation. The 6 cases are reviewed and learning points regarding complication avoidance and management are presented.

Conclusion We report on 6 rare, major complications after VSS for IIH. Familiarity with these potential complications and appropriate timely management may allow for good clinical outcomes.

Disclosures R. Townsend: None. A. Jost: None. M. Amans: None. F. Hui: None. M. Bender: None. S. Satti: None. R. Maurer: None. K. Liu: None. W. Brinjikji: None. K. Fargen: None.

\section{P-041 CHRONIC HEADACHES AND MIDDLE MENINGEAL ARTERY EMBOLIZATION}

J Catapano*, K Karahalios, V Srinivasan, J Baranoski, C Rutledge, T Cole, A Ducruet, F Albuquerque, A Jadhav. Neurosurgery, BNI, Phoenix, AZ

\subsection{6/neurintsurg-2021-SNIS.77}

Background The middle meningeal artery (MMA) has been implicated in chronic headaches, but no studies have examined the relationship between MMA embolization and headaches.

Methods Patients treated with MMA embolization for a chronic subdural hematoma (cSDH) (1/1/2018-12/31/2020) were retrospectively assessed. Patients with a Glasgow Coma Scale (GCS) score of 15 on discharge received a follow-up phone call to assess their history of chronic headache, defined as a headache $\geq 2$ years before the $\mathrm{cSDH}$ and symptoms $\geq 2$ days/month. A Headache Impact Test (HIT-6) was performed during the follow-up phone call. The primary outcome was resolution or improvement of headaches after embolization.

Results Of 76 patients undergoing MMA embolization for a cSDH during the study period, 56 (74\%) had a discharge GCS of 15 . Of these 56 patients, 46 (82\%) responded to a follow-up phone call and were analyzed (mean (SD) age, 68 (11) years; 36 (78\%) men and 10 (22\%) women). Nine
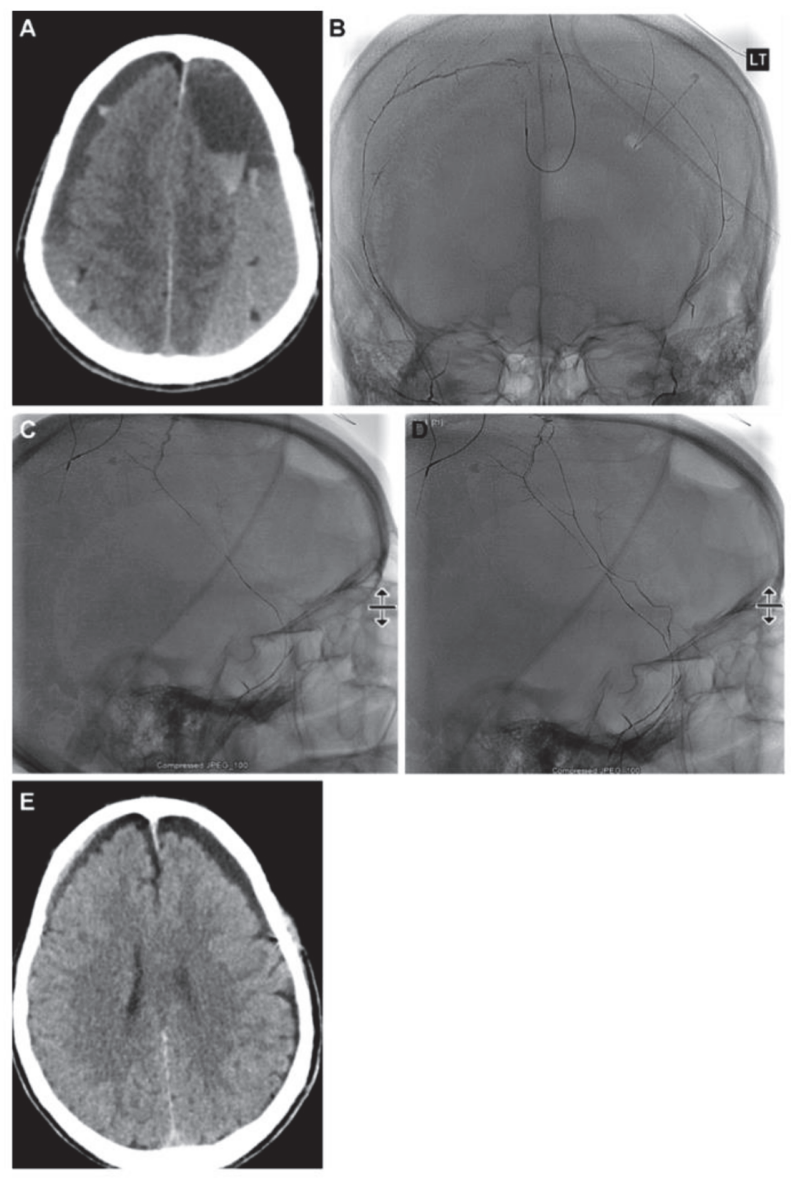

Abstract P-041 Figure 1 (A) Axial computed tomogram (CT) of the head showing bilateral chronic subdural hematomas (CSDHs). (B-D) Cerebral angiography images showing bilateral middle meningeal artery embolization with Onyx (views: B, un-subtracted posteroanterior; C, right lateral, D, left lateral). (E) Axial head $\mathrm{CT}$ at 30-day follow-up shows significant improvement of bilateral CSDHs. Used with permission from barrow neurological institute, Phoenix, Arizona 